\title{
Worldwide fight against COVID-19 using nanotechnology, polymer science, and 3D printing technology
}

\author{
Shadpour Mallakpour ${ }^{1}$ (D) $\cdot$ Vajiheh Behranvand $^{1}$. \\ Chaudhery Mustansar Hussain ${ }^{2}$
}

Received: 29 July 2021 / Revised: 2 December 2021 / Accepted: 3 December 2021 /

Published online: 28 January 2022

(c) The Author(s), under exclusive licence to Springer-Verlag GmbH Germany, part of Springer Nature 2021

\begin{abstract}
One of the lethal illnesses that humanity has ever seen is COVID-19 irrefutably. The speed of virus spread is high and happens through polluted surfaces, respiratory droplets, and bodily fluids. It was found that without an efficient vaccine or specific treatment using personal protective equipment, preventing contamination of hands, and social distancing are the best ways to stay safe during the present pandemic. In this line, polymers, nanotechnology, and additive manufacturing, or 3D printing technology have been considered to probe, sense, and treat COVID-19. All aforementioned fields showed undeniable roles during the COVID-19 pandemic, which their contributions have been reviewed here. Finally, the effect of COVID-19 on the environment, alongside its positive and negative effects has been mentioned.
\end{abstract}

Keywords Nanostructures · Polymeric materials $\cdot 3 \mathrm{D}$ printing technology $\cdot$ COVID19

\section{Introduction to global disaster}

The question that has been asked among students for a long time, even in the essay class, is "Is science better or wealth?" Perhaps the answer to this question can be found in today's difficult situation, that is, COVID-19 pandemic. The name Latin derived "corona" means "wreath" or "crown." SARS-CoV-2 has known as the seventh coronavirus, which causes severe respiratory disease and is transmitted mainly through respiratory droplets and fomites, and potentially aerosols. COVID-19

Shadpour Mallakpour

mallak@iut.ac.ir; mallak777@yahoo.com

1 Organic Polymer Chemistry Research Laboratory, Department of Chemistry, Isfahan University of Technology, Isfahan 84156-83111, Islamic Republic of Iran

2 Department of Chemistry and Environmental Science, New Jersey Institute of Technology, Newark, NJ 07102, USA 
consists of four main structural proteins of the spike (S), nucleocapsid (N), membrane (M), and envelope (E) (Fig. 1). By binding the spike (S) glycoprotein to the complementary host cell receptor, the infection starts $[1,2]$. The first report of this disease was presented in late December 2019 in Wuhan, China, and was observed in patients with symptoms such as fever, cough, and difficult breathing. Till now, 218 countries and territories around the world and 2 international conveyances have been affected by the COVID-19, and unfortunately, 5,151,367 people have died till November 19, 2021, according to the site of "https://www.worldometers.info/coron avirus/." From the beginning, scientists have examined and studied the function of the virus to can find effective ways to deal with it. They found that during the present pandemic in the absence of an efficient vaccine in place, the most available resources of respiratory protection would be infectious personal protective equipment (PPE) such as masks, various types of face coverings, respirators, and gloves [3-5].

This is where the science of polymer, nanotechnology, and 3D printing came in and rushed to the aid of human beings and scientists so they can design lots of tools and materials to probe, sense, and treat COVID-19 (Fig. 1). The goal of the current study is to represent the role of these three fields, their applications, and their participation in the fight against the COVID-19.

\section{The role of polymers in the COVID-19 pandemic}

The role and importance of polymeric materials in human life are not hidden and these valuable materials are a part of our daily life. Polymers are extensively used because of formability, cost-effectiveness, more resistance to chemicals rather than metals, variety, biocompatibility, and biodegradability in some cases. It was

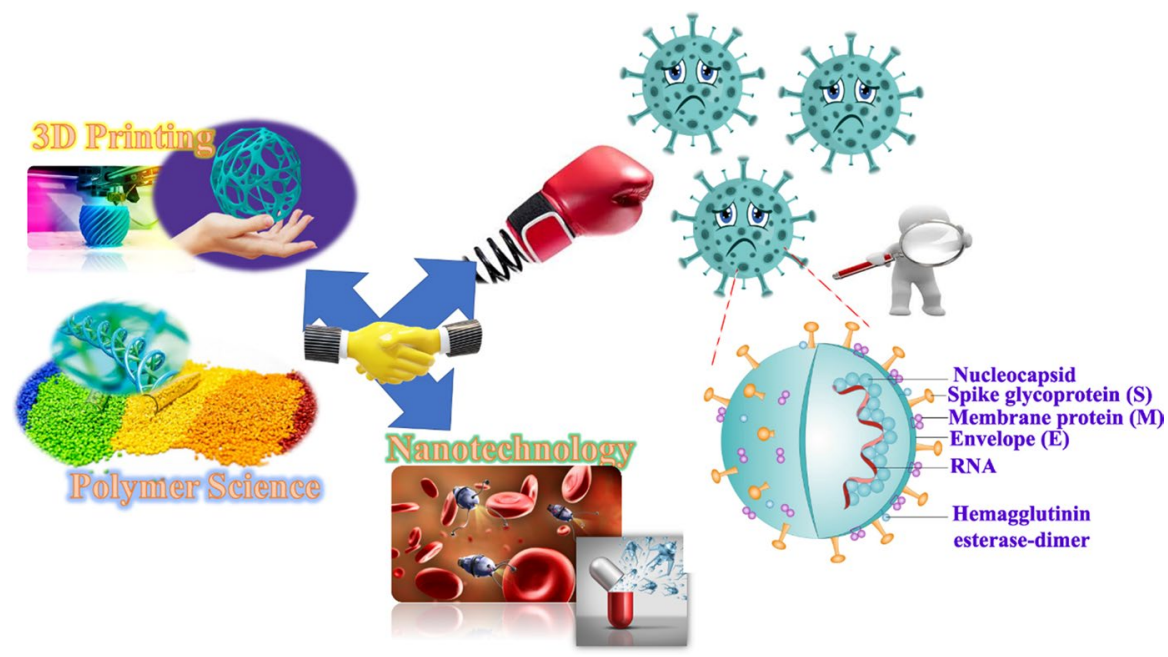

Fig. 1 Contribution of three fields in the fight against COVID-19 [1] 
mentioned the best way of safety against this virus is using PPEs to decrease the infection risk since they act as a barrier from bacteria and viruses. Different equipment is needed for the medical professionals such as masks, gloves, and goggles are shown in Fig. 2, which will be discussed from a point of structure and kind view in the next section. The basic component of this equipment is polymeric materials, for instance poly(ethylene terephthalate) (PET), polypropylene (PP), polyethylene (PE) latex, acrylonitrile butadiene rubber (known as nitrile), poly(vinyl chloride) (PVC), and so forth. Also, the application of polymers in coating and sensors will be discussed.

\section{Gloves}

Different types of gloves are used for example latex, nitrile, vinyl-polyvinyl, neoprene, PE, and among them,nitrile, neoprene, vinyl, and latex are usually applied in geochemical and biological laboratories (Fig. 3A). The mentioned materials alongside their properties and applications have been listed by Anedda and coworkers in Table 1 [6-8].

\section{Latex}

An emulsion of a mix of proteins and compounds is Latex, which is found in $10 \%$ of all flowering plants and is known as natural rubber, but synthetic latexes are common too (Fig. 3A). After harvesting the sap of a rubber tree and preserving it with ammonia, purification and concentrating are done to remove water and impurities. Then it is mixed with further processing chemicals to obtain latex useful for glove production. The advantages of this kind of gloves are biodegradability, elasticity, comfortability, and the highest level of protection against viruses. Despite these valuable properties of latex gloves, some people react to the proteins in natural latex

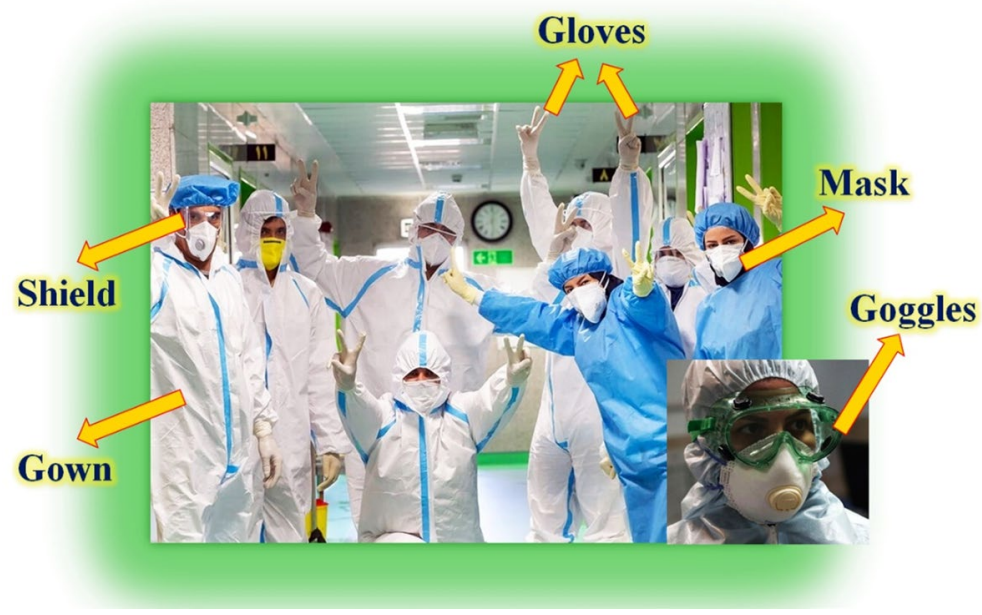

Fig. 2 Examples of personal protective equipment (PPE) 
(A)
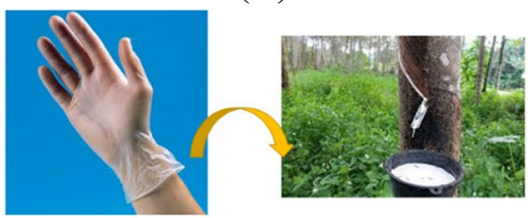

Latex

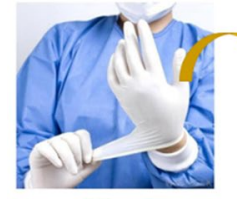

Vinyl

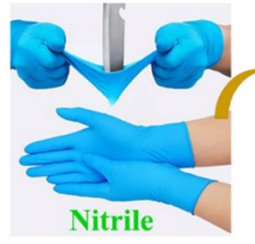

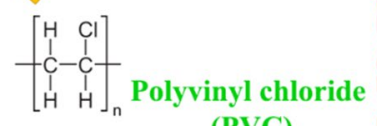

(PVC)

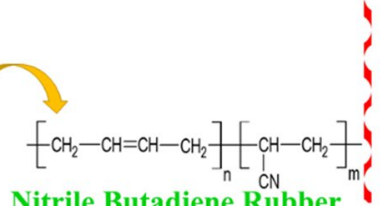

(NBR)
(B)

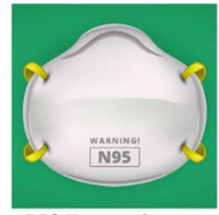

N95 respirator

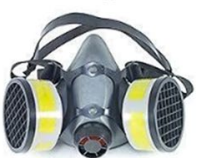

Elastomeric respirator

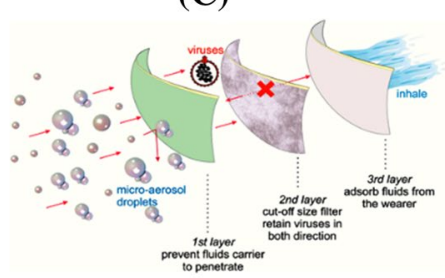

Fig. 3 A Most common gloves and their sources, B different kinds of masks during the COVID-19 pandemic, and $\mathbf{C}$ illustration of the three layers of a surgical face mask to prevent micro-aerosol droplets containing contagious viruses [24]

and have an allergy to it so they prefer to select nitrile or vinyl gloves [9, 10]. It is worth mentioning that increasing the use of gloves especially in pandemics encourages scientists to focus on the study of biodegradability and shelf life of gloves based on starch-filled natural rubber latex (PFNRL) [11]. The shelf life of the PFNRL gloves was estimated to be around 3 years under accelerated aging conditions. This approach can decrease the time of degradation of gloves compared to both commercial latex and commercial synthetic nitrile gloves as shown in Fig. 4 [12].

\section{Nitrile}

Another kind of gloves is nitrile butadiene rubber (NBR), a copolymer of butadiene and acrylonitrile (Fig. 3A), which are more resistant to chemicals, solvents, oils, and fats, have better mechanical properties, and less elastic nature compared to the latex ones. Generally, increasing the nitrile content increases the chemical resistance, but reduces flexibility [13]. The nitrile gloves are the most expensive of other kinds of gloves and this is the only disadvantage of them.

\section{Vinyl}

Petroleum-based gloves which are made from PVC are non-biodegradable, costeffective, and have a longer shelf life rather than latex gloves (Fig. 3A). The 
Table 1 Different glove materials and characteristics [6]

\begin{tabular}{|c|c|}
\hline Type of glove & Indication \\
\hline Latex & $\begin{array}{l}\text { Used in maneuvers with high biological risk, that is, when it is necessary to handle } \\
\text { blood or body fluids in a repeated or prolonged way } \\
\text { Good protection against pathogen } \\
\text { High tensile stretch, best fit and sense of touch, extremely flexible } \\
\text { Contraindicated in latex allergy; should not be used with organic soils, oils, gas, or } \\
\text { grease }\end{array}$ \\
\hline Nitrile & $\begin{array}{l}\text { Alternative to latex, especially if allergic to latex, for high-biological-risk proce- } \\
\text { dures } \\
\text { Moderate protection against pathogens } \\
\text { High puncture and chemical resistance; good comfort, soft and flexible, but stiffer } \\
\text { than latex } \\
\text { More expensive option }\end{array}$ \\
\hline Vinyl-polyvinyl & $\begin{array}{l}\text { Use in case of low biological risk (low protection against pathogens), for patient } \\
\text { cleaning activities } \\
\text { Food prep (low heat) } \\
\text { Average resistance to chemicals (alcohols), low tensile strength } \\
\text { Less expensive option }\end{array}$ \\
\hline Polyethylene & $\begin{array}{l}\text { Only maneuvers where one-handed and short-lasting sterility is required (intravesi- } \\
\text { cal catheterization, endotracheal aspiration) } \\
\text { Loose fit, ideal for frequent glove change, but low protection against hazardous } \\
\text { materials } \\
\text { Very economical }\end{array}$ \\
\hline Synthetic gloves & $\begin{array}{l}\text { Latex- and polyvinyl-free surgical or diagnostic gloves } \\
\text { Very loose, no protection against pathogens } \\
\text { Least expensive option }\end{array}$ \\
\hline Rubber or neoprene & $\begin{array}{l}\text { Used to prepare surgical instruments and endoscopes for disinfection, cleaning of } \\
\text { environments } \\
\text { High mechanical resistance }\end{array}$ \\
\hline
\end{tabular}

Gloves used for household activities in the community, although made of the same materials (e.g., gloves made from natural latex, nitrile, vinyl, and polyethylene) usually do not meet the standards described for medical gloves that are used in health care

penetration of virus to vinyl and latex gloves has been reported many years ago, and the results showed that some vinyl and latex examination gloves permit viral leakage. The holes can be created through actions associated with routine patient maintenance. Under the tested conditions, latex gloves were less vulnerable to hole formation than vinyl gloves [14-16]. So, it has been suggested to wash the hands after glove removal. It seems that this important subject needs more attention, examinations, and updated results. 


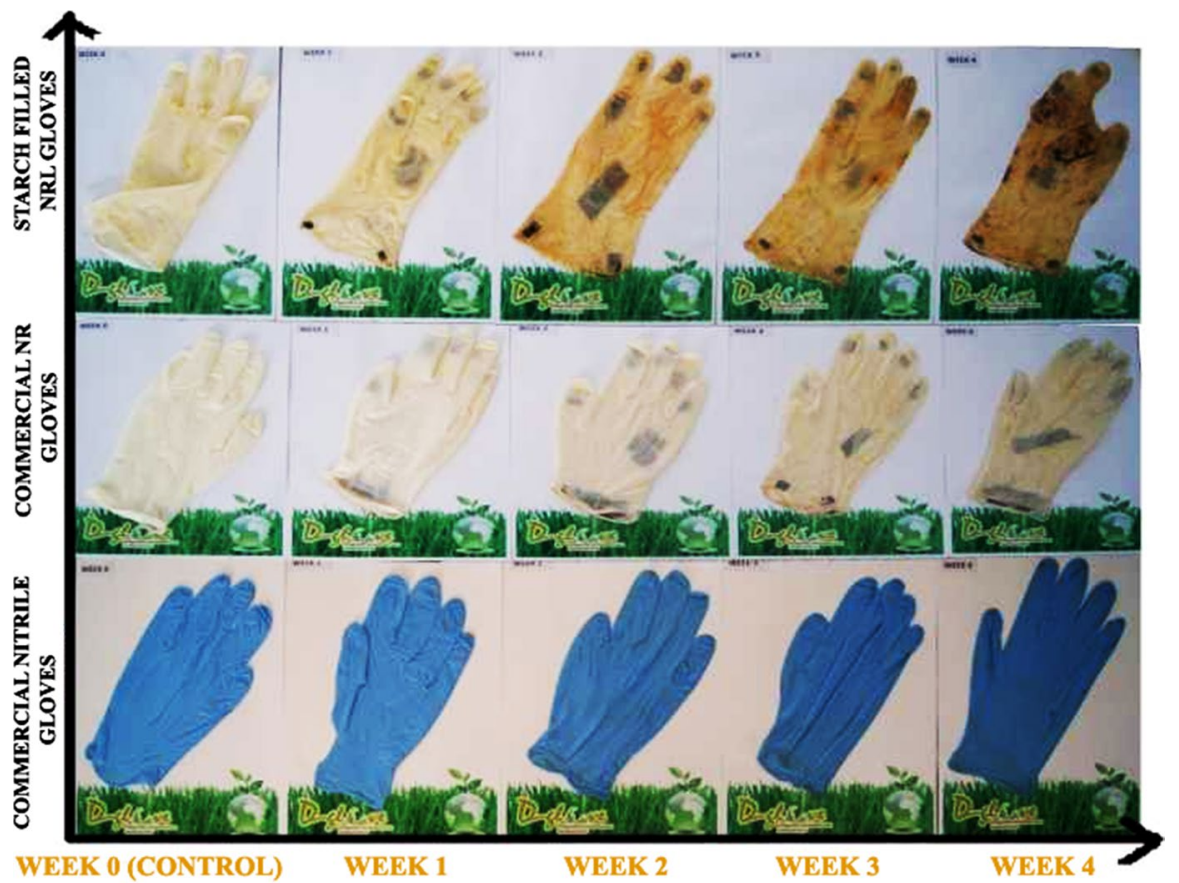

NRL: Natural Rubber Latex

Fig. 4 Effect of biodegradation on Biodegradable Gloves (starch-filled NRL gloves), Commercial NRL gloves and Commercial Synthetic NBR gloves [12]

\section{Gown, shield, goggles}

To keep safe all exposed bodies and inhibit their contact with clothing, blood, and body fluids, the usage of gowns and aprons as protective clothing is suggested. There are two categories of disposable and reusable gowns. Usually, PP fibers consist of bonded three layers by the fusion procedure are employed for the preparation of disposable gowns and permit the vapors or gases pass, but limit the passage of liquids. So, their resistance to pathogens is low and can be overwhelmed via finishing by polyurethane or PVC. On the other hand, polyester and cotton are used for the production of reusable gowns. To make them proper for various washing cycles, fabrics made up of microfilament yarns, with continuous polyester fibers, appeared, where carbon fibers are incorporated during weaving [17].

Thermoplastic polymers such as PET, PVC, and polycarbonate (PC) can preserve transparency besides chemicals, heat, and impact resistance and are a suitable candidate for the manufacture of face shields [18]. PC is the most common polymer for the synthesis of lenses in safety glasses as well owing to its cost-effectiveness, lightweight, UV shield effect, and high impact resistance [19].

Complete protection against ocular COVID-19 transmission cannot provide completely via goggle or face shield, and a modern way by using polymer-based eye drops is proposed. Various mechanisms of suggested polymers that can inhibit 


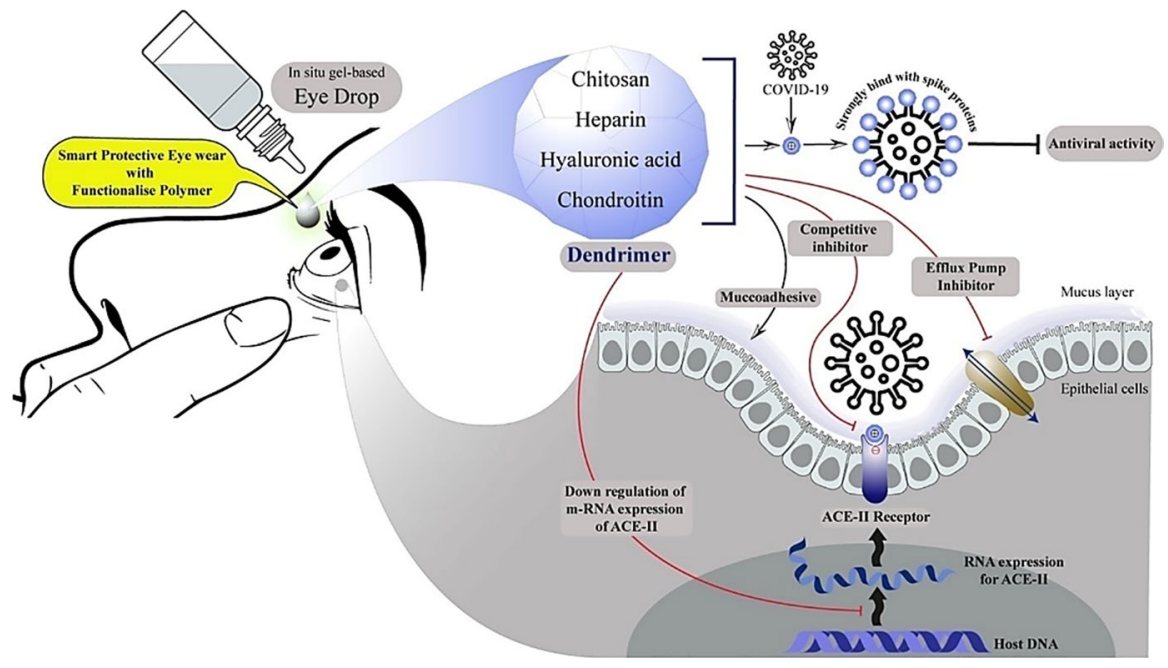

Fig. 5 Multifunctional aspects of mucoadhesive polymers preventing ocular transmission of COVID-19 [20]

ocular COVID-19 transmission are presented in Fig. 5 [20]. Potential antiviral activities can be observed in most of the natural polysaccharides such as chitosan, heparin, dextran, hyaluronic acid, and dendrimers and they are biodegradable, biocompatible, non-toxic, and non-immunogenic. They can bind to ACE-2 receptorsknown as a cellular doorway for the COVID-19-and supply highly potential trails to block virus entry to host cells [21].

\section{Masks}

To minimize the transmission of the virus, it has been believed that social distancing, eye protection, and wearing a face mask are crucial. The most common face masks used these days are cloth-based masks, surgical masks, N95 respirators, and elastomeric respirators (Fig. 3B).

\section{Cloth-based mask}

This kind of mask, which is mainly prepared from cotton, is not suggested in hospital environments because they are mostly produced based on non-standard methods. However, the Centers for Disease Control and Prevention (CDC) recommends wearing a cloth mask or even a scarf to decrease respiratory emissions from an infected person $[18,22]$. 


\section{Surgical mask}

A surgical mask has been composed of three layers with different functions as shown in Fig. 3C. It can be made of viscose, polyester, PP, etc., and nonwoven fibers with spunbonded-meltbonded-spunbonded (SMS) structures as the highest level of protection. In the absence of PP fibers, poly(vinylidene fluoride) and polytetrafluoroethylene can be used as microporous membranes. In a surgical mask, hydrophobicity is provided by the outer layer, the middle layer has a filtering role, and the inner layer absorbs droplets coming from the wearer [18, 23, 24].

\section{N95 respirator}

In comparison with the conventional mask, higher filtering effectiveness and a better fit can be provided by a respirator or filtering device. According to the tests of the National Institute for Occupational Safety and Health (NIOSH), there are R (resistant to oil), $\mathrm{N}$ (not oil resistant), and $\mathrm{P}$ (oil proof) series with different filtration efficacy levels of 95, 99, and 99.97\% (for particles of $300 \mathrm{~nm}$ ), and among them, N95 respirators are used commonly. It has been made of three layers the middle layer act as a filter fabricated from nylon, cotton, polyester, and PP. It is while the most extensively employed polymer is PP owing to good mechanical features, simple processing, and efficient species in filtration devices [25-27].

The efficiency of filtration can be enhanced by filter layer modification with nanomaterials which will be discussed in Sect. 3 .

\section{Antiviral polymers}

The researches have shown that the sustainability of COVID-19 virus on polymeric materials is more than other surfaces which is a major reason for its transmission. Therefore using polymers that exhibit intrinsic antiviral activity has been attention. These polymers can bind to the virus and prevent it from invading a host cell. The natural and synthetic polymers as well as metal and metal oxide NPs and their composites have been known as efficient antiviral agents [28-30]. For example, polyurethane $/ \mathrm{Cu}_{2} \mathrm{O}$ coating could inactivate the $99.9 \%$ viruses after $1 \mathrm{~h}$ compared to the uncoated sample [31]. Biopolymers such as chitosan and chitin have shown a promising role in coping with viral infection in triple approaches of direct antiviral activities, the immune system-associated influences as well as vehicles for drug delivery [32-34]. There is an important feature in the polymeric materials that can lead to antiviral activity and that is the presence of functional groups in their structures. For example, highly positively charged polylysine molecules have represented a strong electrostatic interaction with COVID-19 spikes and prevent their replication [35].

\section{Polymers in sensor and biosensor}

Compared to other materials such as metal oxides, carbonaceous compounds, and gold nanoparticles, conducting polymers exhibit promising features owing to having 
$\pi$ bonds and chain conformation alterations, which cause to be sensitive and selective for special biological molecules [36]. Also, for the enhancement of sensitivity and detection limit, the combination of polymers and nanomaterials can be applied to modify the electrode, for example a sensor platform based on polypyrrole (a conductive polymer) and gold nanoparticles for monitoring of SARS-CoV-2 infection [37]. The designed flexible biosensor showed significant selectivity, specificity, and sensitivity for SARS-CoV-2.

The field of sensing using molecularly imprinted polymers (MIPs) has been paying attention due to their thermal, physical, and chemical stabilities. They have recognition sites and act as receptors via "lock and key" method, and sensors based on MIP molecules can detect SARS-CoV-2 antigen rapidly [38-40]. Polypyrrole can be simply electropolymerized and employed as a polymeric matrix of MIPs-based sensor for the determination of glycoprotein of SARS-CoV-2-S [41]. More sensitivity to the SARS-CoV-2-S spike glycoprotein was obtained for a sensor based on MIP polypyrrole in comparison with the polypyrrole without imprint sensor, which is because of the presence of specific molecular recognition sites that are formed during molecular imprinting.

\section{The role of nanotechnology in COVID-19 pandemic}

There is a similar scale between COVID-19 virus in diameter around 60-140 nm with nanomaterials so the interactions between two species can be effective and suggest an enormous potential in detection and treatment approaches of COVID-19 as well as PPE improvement [42, 43].

An important species of a mask is having an efficient filter. Interception, inertial impact, diffusion, gravitation, and electrostatic attraction are the main mechanisms that have been explained for air filtration. Nanofibers have a high specific surface area and high porosity, which rise the promises of particulate substance deposition $[22,44,45]$. An antiviral bio-based face mask was made from the mixing of licorice root extract with poly(vinyl alcohol) (PVA) via electrospinning method [46]. The prepared filter not only had porosity less than the COVID-19 size but also glycyrrhizinic acid present in the extract can deactivate the virus and stop replication. In another study, a nanofiber membrane from electrospinning of wheat gluten/PVA reinforced with gluten-derived carbon nanofiber was proposed (Fig. 6A) [47]. The obtained mask is effective in pandemics, and due to its bionature, it will decrease environmental pollution.

Nanofibers based on cellulose acetate (CA) and polyvinylidene fluoride (PVDF) nanofiber-coated PP spunbonded layers were prepared as a layer for N95 respirators [48]. Due to the bulky structure of CA, its single layer can meet the NIOSH requirements, but for PVDF, double-layered face-to-face PVDF nanofiber mats are needed according to NIOSH owing to the thinner thickness of PVDF nanofibers. Graphene functionalized commercial surgical masks were designed with unique possessions as shown in Fig. 7a [49]. By a few layers of graphene coating (according to Raman spectrum, Fig. 7d), the smooth surface of nanofibers changed to the rough surface (Fig. 7b, c), which increased the contact angle from $110^{\circ}$ to $141^{\circ}$ and provided 


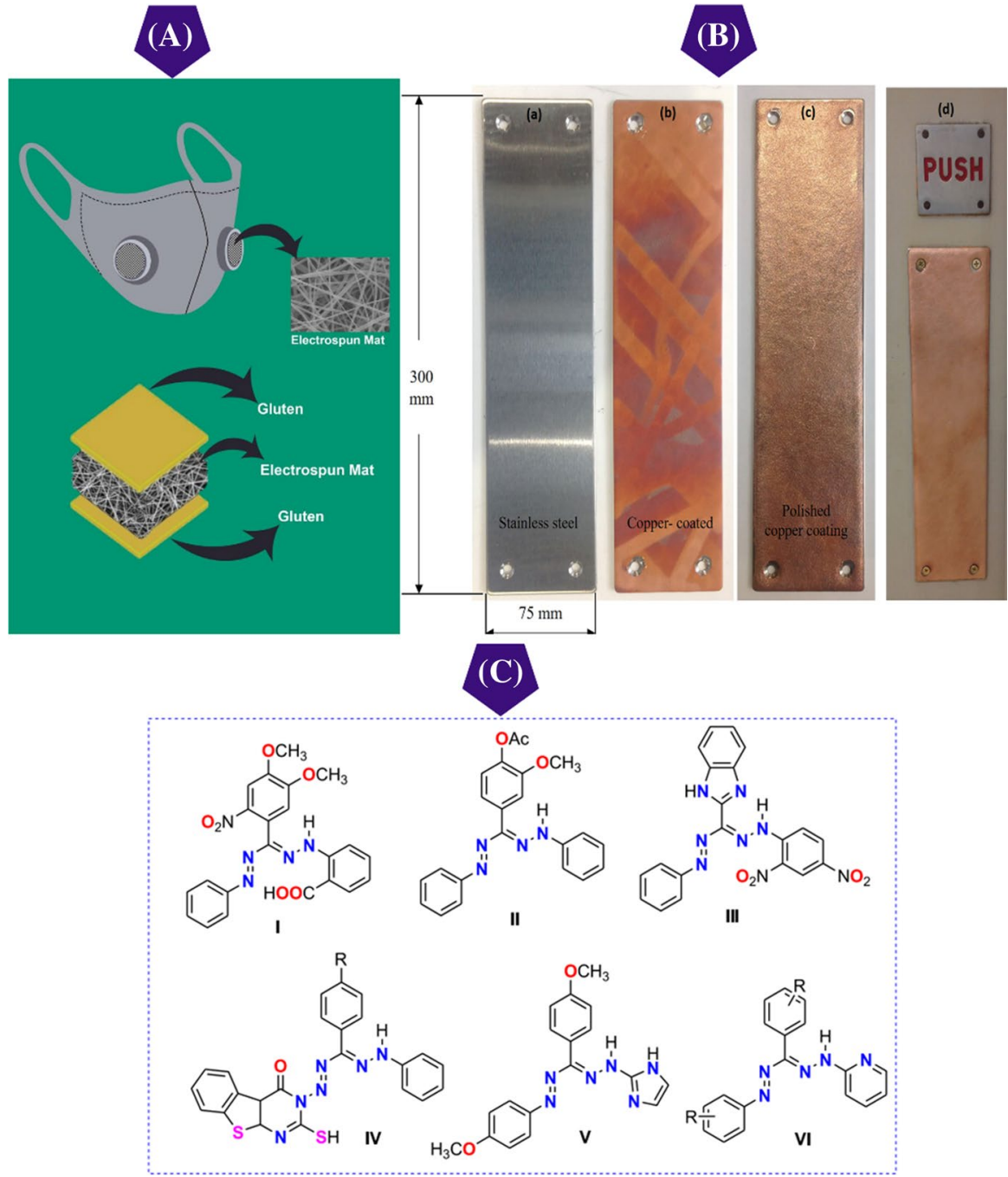

Fig. 6 A Schematic showing the final shape and internal structure of the potential facemasks [47], B macro-photograph of (a) an in-use stainless steel push plate, (b) copper coating on stainless steel push plate, (c) polished copper coating; and (d) copper-coated push plate installed on a door [54], and $\mathbf{C}$ some reported antiviral and antimicrobial formazans [56]

superhydrophobicity (Fig. 7e, f). This causes free moving of water droplets on the mask's surfaces and improving the self-cleaning performance (Fig. $7 \mathrm{~g}$ ). On the other hand, under sunlight illumination, a quick increase in the surface temperature of the prepared mask to over $80{ }^{\circ} \mathrm{C}$ causes sunlight sterilization, which provides a reusable mask. Nanocellulose is one of the great candidates for filtration of COVID19. For improvement of its ability for viral filtration, its surface can be modified to make it positively charged. In this way, it can create electrostatic interaction with 


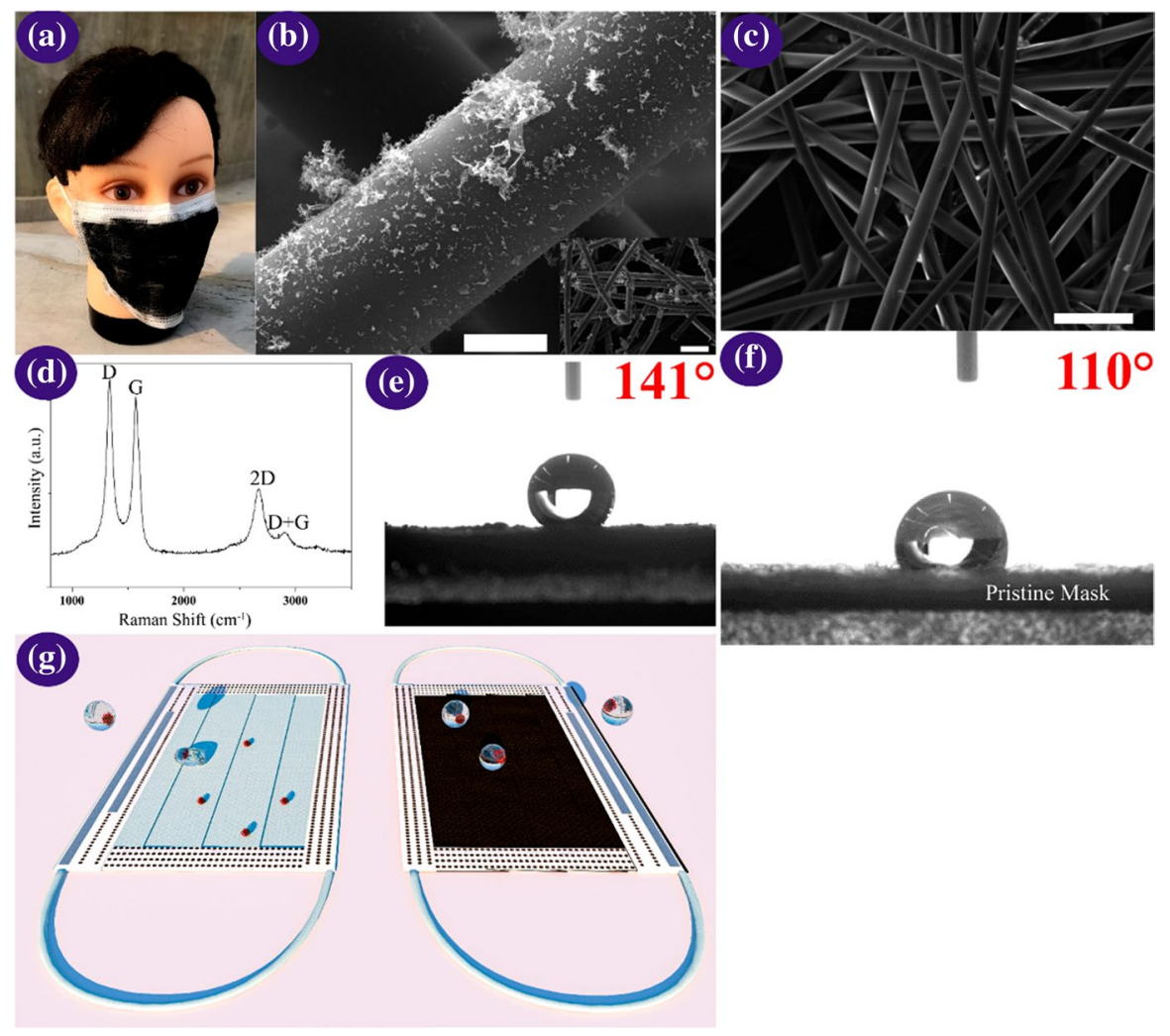

Fig. 7 a Optical image of the laser-fabricated graphene mask. b SEM of the graphene-coated nonwoven fiber within the surgical mask; scale bar is $10 \mu \mathrm{m}$. The inset is a zoom-out image, with the scale bar at $100 \mu \mathrm{m}$. c SEM image of the nonwoven fibers from a pristine surgical mask; the scale bar is $100 \mu \mathrm{m}$. d Raman spectrum of the graphene-coated mask. e Water contact angle on the graphene-coated mask. $\mathbf{f}$ Water contact angle measurement of the pristine surgical mask. And $\mathbf{g}$ Illustration of the self-cleaning properties of the black graphene-coated mask (right), compared to the pristine blue mask (left) [49]

negatively charged viruses such as COVID-19 effectively [50]. Novel charged PVDF nanofiber filters were manufactured and could capture at least $90 \%$ of the COVID-19 stimulated by the 100-nm sodium chloride aerosols [51]. The designed filters can be excellent devices for capturing airborne COVID-19 with an average size of $100 \mathrm{~nm}$ via Coulombic attraction.

To diminish the COVID-19 transmission to a vulnerable host in public places, developing antimicrobial coating with NPs and on PPE would be an effective way. Coating agents cross the microbial membrane and interfere with the metabolic path to prevent microbes be attached to the surface $[52,53]$. In this line, the effect of copper particle coating on in-use steel parts (as shown in Fig. 6a-d, part B) on the inactivation time of COVID-19 was studied [54]. The results showed a significant reduction in the lifetime of the COVID-19 virus to less than $5 \mathrm{~h}$. It does not need to replace the entire touch surface with copper material when using the cold-spray technique because copper coating only needs a short time in minutes. 
Due to comparable bioavailability, low toxicity, and scavenger properties of nanoselenium (nanoSe), its antiviral potential in combating COVID-19 was investigated [55]. The main concern about most nanomaterials is their toxicity. The median lethal dose (LD50) of nanoSe in mice was very lower than that of selenite and SeMet. So, it can be applied for antiviral drug carrier after more experiments. A molecular docking study was done for estimation of the binding affinity of nanoformazan derivatives with COVID-19 and the findings showed deeply creating stable complexes in the active site of COVID-19, so their employment as antiviral agents would be helpful [56]. Some of formazans derivatives are shown in Fig. 6C. Another herbal-based agent is nanocurcumin that prevent the manufacture of reactive oxygen species (ROS) in macrophage and affect the immune system [57]. By comparison of a healthy person and COVID-19 infected patients, a higher level of pro-inflammatory cytokines was observed for patients and because one of the strongest anti-inflammatory agents is curcumin it could decrease the mortality rate.

A docking study showed efficient interaction of $\mathrm{Fe}_{2} \mathrm{O}_{3}$ and $\mathrm{Fe}_{3} \mathrm{O}_{4}$ NPs with the spike protein receptor-binding domain of COVID-19, which will change the conformation of the viral proteins and inactivate the viral finally [58]. It has been reviewed that green synthesized gold NPs can be useful for the diagnosis and treatment of viral infections as well [59]. Graphene and its derivatives are containing hydroxy, epoxy, and carboxylic acid groups besides having a conjugated network that can simplify their interaction with viruses and their destruction. These nanostructures also can be employed as piezoelectric immunosensor, which work according to variations in the mass of the piezoelectric graphene crystal for detection of the COVID19 virus [60-62].

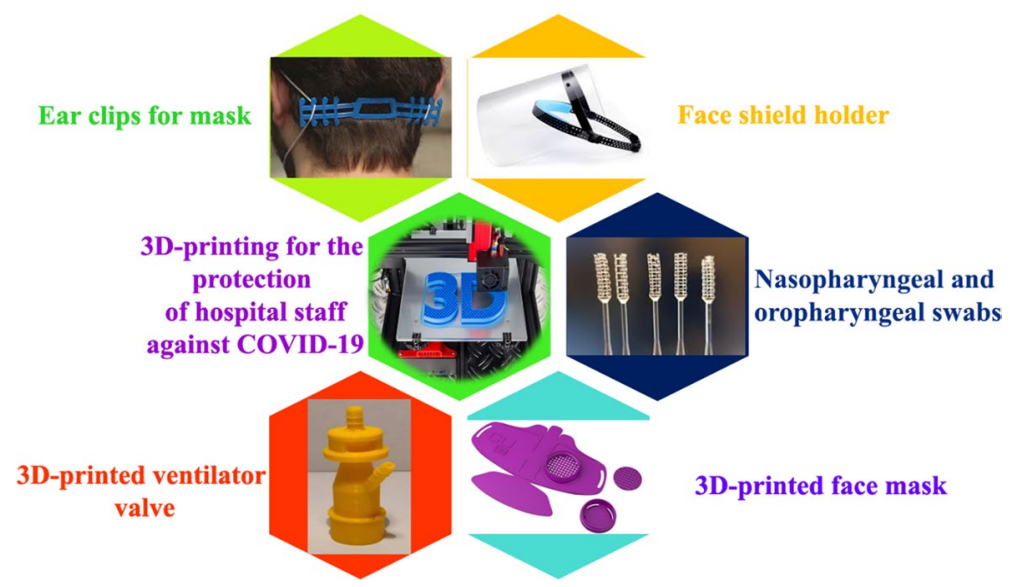

Fig. 8 Different equipment uses in COVID-19 pandemic produced by 3D printing 


\section{The role of 3D printing technology in COVID-19 pandemic}

$3 \mathrm{D}$ printing is a commonly used replacement of the additive manufacturing word and has been interested recently. During pandemic demand for using PPE such as face shield holder, N95 respirator masks as well as ventilator valves, and testing kits. highly increased. 3D printing as an innovative technology not only could eliminate shortcomings, accelerate device production, but also is useful for the fabrication of complex architectures [63-65]. Some of the essential equipments manufactured by 3D printing during the COVID-19 pandemic are shown in Fig. 8.

Among all the 3D printing technologies, fused deposition modeling, also named fused filament fabrication, is the most common that uses thermoplastics of acrylonitrile butadiene styrene (ABS) and polylactic acid (PLA) mostly. Presently, PLA is a widely used polymer due to its recyclability and biocompatibility features [66-69].

The role of the three fields of polymer, nanotechnology, and 3D printing can be seen in a respiratory mask simultaneously. A kind of mask filter was designed based on PLA and cellulose acetate nanofibrous matrix embedding graphene oxide and $\mathrm{CuO}$ NPs as shown in Fig. 9a and their assembly is observed in Fig. 9c [70]. The airborne viral particles can be stopped by the polymeric network and inactivation of the viral particles is done by the NPs. The fixed piece of a respirator face mask is produced based on the 3D printing technique by heating of PLA (Fig. 9b). Coated air filters with functionalized graphene mounted on a 3D printed facial mask replica were designed to improve antiviral and antimicrobial features [71]. This equipment could filter $98.2 \%$ of bacteria and arrest viral transmission at the functionalized graphene-coated layer completely. Full-face snorkel masks with 3D printed adapters
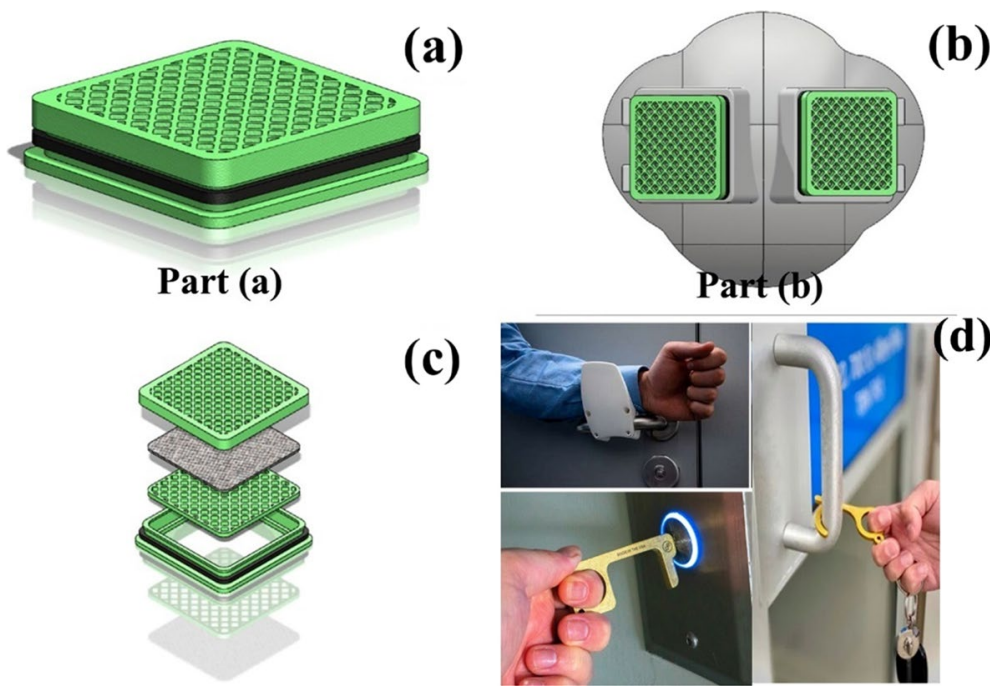

(c)

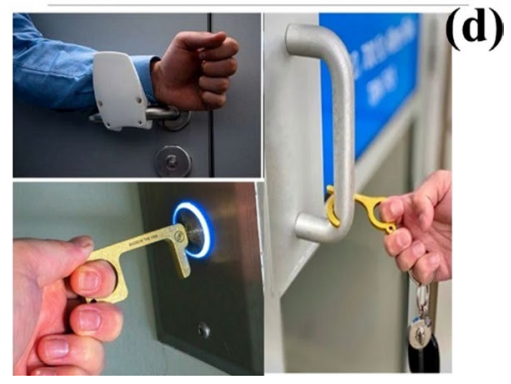

Fig. 9 Schematic representation of the design of the nanofibrous respirator face mask. Part a depicts the respirator filter containing multilayers of CuONPs/GO@PLA and CuONPs/GO@CA nanofibers. Part b represents the fixed part of the face mask. Part $\mathbf{c}$ shows the assembly of the multilayers consisting of nanofibers into a respirator filter [70], and a 3D printed door opener (d) 
have been designed to solve problems about complete eye and face protection, and high-quality air filtration that can be observed in using PPEs [72]. They are not only more cost-effective than commercial $3 \mathrm{M}$ full face respirators but also can minimize fogging problems and $\mathrm{CO}_{2}$ rebreathing.

It has been reported that the COVID-19 virus is stable on the surfaces and its stability is different on the various surfaces. Survival times of this virus are as follow: plastic (72 h), stainless steel surfaces (48 h), copper surfaces $(4 \mathrm{~h})$, cardboard $(24 \mathrm{~h})$, printing/tissue papers $(3 \mathrm{~h})$, wood and cloths $(2 \mathrm{~h})$ [61]. It has been hypothesized that SARS-CoV-2 virus can be inactivated in dryness such as on paper and porous materials. Because plastics have waterproof nature, water droplets remain on the surface and protect the viruses from dryness. Generally, on porous materials like tissue, the half-life of the virus is shorter than non-porous materials such as plastics $[30,73]$. With the help of 3D printing technology, in addition to the manufacture of medical or PPE devices, other devices such as door openers were designed and used to minimize hand contact with the surface (Fig. 9d) [74].

\section{Environment and COVID-19}

According to the above-mentioned information, the effective role of polymers in combating COVID-19 is not hidden from anyone. In this pandemic use of polymeric materials was not limited to the manufacture of PPE equipment such as masks, gloves, gowns, and stuff. In addition to these sources, during the pandemic use of medical packaging wastes generated from households and hospitals increased. Also, due to the rising need for online food and grocery delivery services, consuming food packaging wastes increased considerably. In this way, these materials can be a huge source of macroplastics and microplastic environmental pollution [75, 76]. This important issue can draw attention to the use and development of bioplastics with fast degradability features in the environment, polymer recycling, employing nanomaterials to can increase the reusability cycles, or introducing user-friendly approaches for effective extension of the service time of PPE [77-80].

Despite all the negative impacts of COVID-19 on the environment and human health, its advantages cannot be ignored. During this pandemic decrement in outdoor air pollution contain NOX, COX, Sulfur dioxide $\left(\mathrm{SO}_{2}\right)$, and volatile organic compounds, pollution noise, and energy consumption, returning animals to natural dwellings, and reviving of the ozone layer to some extent occurred [81-83].

\section{Conclusions}

The latest developments in the roles of nanotechnology, polymer science, and additive manufacturing in combating COVID-19 were highlighted here. This review explains the role of these three important fields in this virus pandemic with some examples to make tangible their effects and can help readers understand how this contribution and harmony could get closer to the world to combat COVID-19. It was shown that polymers can provide the simplest and most essential personal equipment 
such as masks, gloves, gowns, and respirators. For the enhancement of polymer capability nanostructures have an efficient role. Some complex medical devices cannot be simply manufactured using conventional producing ways, but additive manufacturing as an innovative technology supplies these complex structures.

Increasing environmental pollution by polymeric materials and hospital wastes needs more attention from governments and scientists. Focus on the development of biodegradable materials, increasing the reusability cycles, and presenting the accessible approaches for extension of the service time of equipment is highly encouraged. Despite the negative effects of COVID-19 on human health whether physically or mentally, the environment, economy, and so forth, it taught humans to protect mother earth better, help each other more, and change bad habits. Also, during this disaster pandemic, some countries, especially those under sanctions, have been able to develop their talents through empathy and cooperation.

Acknowledgements The authors are grateful for the support from the Research Affairs Division of Isfahan University of Technology (IUT), Isfahan. I. R. Iran, and Iran National Science Foundation (INSF), Tehran, I. R. Iran (Grant Number 98015398), and Iran Nanotechnology Initiative Council (INIC) Tehran, I. R. Iran. They would like to thank the National Elite Foundation (NEF), Tehran, I. R. Iran, and Center of Excellence in Sensors and Green Chemistry IUT, Isfahan. I. R. Iran.

\section{Declarations}

Conflict of interest All authors declare that they have no conflict of interest.

\section{References}

1. Florindo HF, Kleiner R, Vaskovich-Koubi D, Acúrcio RC, Carreira B, Yeini E, Tiram G, Liubomirski Y, Satchi-Fainaro R (2020) Immune-mediated approaches against COVID-19. Nat Nanotechnol 15:630

2. Kumar ND, Mitra M (2020) Herbal gold nanoparticles for attenuating pandemic infection of COVID-19 virus. J Nanomed Nanotechnol 11:9

3. Goyal MK, Gupta AK (2020) Integrated risk of pandemic: Covid-19 impacts, resilience and recommendations. Springer, Berlin

4. Han J, He S (2021) Need for assessing the inhalation of micro(nano)plastic debris shed from masks, respirators, and home-made face coverings during the COVID-19 pandemic. Environ Pollut 268:115728

5. Mallakpour S, Azadi E, Hussain CM (2021) The latest strategies in the fight against the COVID-19 pandemic: the role of metal and metal oxide nanoparticles. New J Chem 45:6167-6179

6. Anedda J, Ferreli C, Rongioletti F, Atzori L (2020) Changing gears: Medical gloves in the era of coronavirus disease 2019 pandemic. Clin Dermatol 38:734-736

7. Garçon M, Sauzéat L, Carlson RW, Shirey SB, Simon M, Balter V, Boyet M (2017) Nitrile, Latex, Neoprene and Vinyl gloves: a primary source of contamination for trace element and $\mathrm{Zn}$ isotopic analyses in geological and biological samples. Geostand Geoanal Res 41:367-380

8. Jędruchniewicz K, Ok YS, Oleszczuk P (2021) COVID-19 discarded disposable gloves as a source and a vector of pollutants in the environment. J Hazard Mater 417:125938

9. DeFusco AJ, Sehgal KC, Bassett DR (1997) Polymeric dispersions: principles and applications. Asua JM (Eds) Kluwer Academic Publishers, pp. 379-396

10. Meleth JP (2012) LAP LAMBERT Academic Publishing, 2012, pp. 1-16

11. Rahman MFA, Rusli A, Misman MA, Rashid AA (2020) Biodegradable gloves for waste management post-COVID-19 outbreak: a shelf-life prediction. ACS Omega 5:30329-30335 
12. Misman MA, Azura AR (2014) Overview on the potential of biodegradable natural rubber latex gloves for commercialization. Adv Mater Res 844:486

13. Tan KY, Phang SW, Phang CK, Lang Choh J, Pang Goh C, Ban Wong C, Ting Tee T (2018) Preliminary study on effect of chemical composition alteration on elastic recovery and stress recovery of nitrile gloves. MATEC Web Conf 152:1

14. Korniewicz DM, Laughon BE, Cyr WH, Lytle CD, Larson E (1990) Leakage of virus through used vinyl and latex examination gloves. J Clin Microbiol 28:787

15. Mallakpour S, Abdolmaleki A, Tabebordbar H (2016) Production of PVC/ $\alpha-\mathrm{MnO}_{2}-\mathrm{KH} 550$ nanocomposite films: morphology, thermal, mechanical and $\mathrm{Pb}$ (II) adsorption properties. Eur Polym $\mathrm{J}$ $78: 141-152$

16. O'Connell KP, El-Masri M, Broyles JB, Korniewicz DM (2004) Testing for viral penetration of non-latex surgical and examination gloves: a comparison of three methods. Clin Microbiol Infect 10:322

17. Fangueiro R, Ferreira DP, Costa SM, Araújo J (2020) Protective gowns, Costa, in Fibrenamics Intell., Fibrenamics_UMinho, 2020, pp. 1-30

18. Corrêa HL, Corrêa DG (2020) Polymer applications for medical care in the COVID-19 pandemic crisis: will we still speak ill of these materials? Front Mater 7:1

19. Jankovic J, Ogle BR, Zontek TL, Biegalski MD, Hollenbeck SM, Wells TM (2016) Suitability of polycarbonate safety glasses for UV laser eye protection. J Chem Heal Saf 23:29

20. Kumar SD, Pradhan D, Kumar P, Kar B, Ghosh G (2020) Smart polymeric eye gear: A possible preventive measure against ocular transmission of COVID-19. Med Hypotheses 144:110288

21. Chakhalian D, Shultz RB, Miles CE, Kohn J (2020) Opportunities for biomaterials to address the challenges of COVID-19. J Biomed Mater Res Part A 108:1974

22. Chua MH, Cheng W, Goh SS, Kong J, Li B, Lim JYC, Mao L, Wang S, Xue K, Yang L, Ye E, Zhang K, Chet W, Cheong D, Tan H, Li Z, Tan BH (2020) Face masks in the new COVID-19 normal: materials, testing, and perspectives. Research 2020:7286735

23. Alam SM, Islam S (2020) The implication of textile materials applied in preventing the spread of COVID-19. Biomed J Sci Tech Res 28:22009

24. Wibisono Y, Fadila CR, Saiful S (2020) Facile approaches of polymeric face masks reuse and reinforcements for micro-aerosol droplets and viruses filtration: a review. Polymers 12:2516

25. Zhang M, Emery AR, Tannyhill RJ, Zheng H, Wang J (2020) Masks or N95 respirators during COVID-19 pandemic-which one should I wear? J Oral Maxillofac Surg 78:2114

26. Wang PL, Roschli A, Paranthaman MP, Theodore M, Cramer CL, Zangmeister C, Zhang Y, Urban JJ, Love L (2021) Recent developments in filtration media and respirator technology in response to COVID-19. MRS Bull 46:822-831

27. Larsen GS, Cheng Y, Daemen LL, Lamichhane TN, Hensley DK, Hong K, Meyer HM, Monaco SJ, Levine AM, Lee RJ, Betters E, Sitzlar K, Heineman J, West J, Lloyd P, Kunc V, Love L, Theodore M, Paranthaman MP (2021) Polymer, additives, and processing effects on N95 filter performance. ACS Appl Polym Mater 3:1022-1031

28. Mallakpour S, Azadi E, Hussain CM (2021) Recent breakthroughs of antibacterial and antiviral protective polymeric materials during COVID-19 pandemic and after pandemic: Coating, packaging, and textile applications. Curr Opin Colloid Interface Sci 55:101480

29. Umar Y, Al-Batty S, Rahman H, Ashwaq O, Sarief A, Sadique Z, Sreekumar PA, Manirul Haque SK (2021) polymeric materials as potential inhibitors against SARS-CoV-2. J Polym Environ 9:1-20

30. Mouritz AP, Galos J, Linklater DP, Ladani RB, Kandare E, Crawford RJ, Ivanova EP (2021) Towards antiviral polymer composites to combat COVID-19 transmission. Nano Select 2:2061-2071

31. Behzadinasab S, Chin A, Hosseini M, Poon L, Ducker WA (2020) A surface coating that rapidly inactivates SARS-CoV-2 ACS. Appl Mater Interfaces 12:34723-34727

32. Safarzadeh M, Sadeghi S, Azizi M, Rastegari-Pouyani M, Pouriran R, Haji Molla Hoseini M (2021) Chitin and chitosan as tools to combat COVID-19: A triple approach. Int J Biol Macromol 183:235-244

33. Mallakpour S, Azadi E, Hussain CM (2021) Chitosan, alginate, hyaluronic acid, gums, and $\beta$-glucan as potent adjuvants and vaccine delivery systems for viral threats including SARSCoV-2: a review. Int J Biol Macromol 182:1931-1940 
34. Sharma N, Modak C, Singh PK, Kumar R, Khatri D, Singh SB (2021) Underscoring the immense potential of chitosan in fighting a wide spectrum of viruses: a plausible molecule against SARSCoV- 2? Int J Biol Macromol 179:33-44

35. Stagi L, De Forni D, Malfatti L, Caboi F, Salis A, Poddesu B, Cugia G, Lori F, Gallerie G, Innocenzi P (2021) Effective SARS-CoV-2 antiviral activity of hyperbranched polylysine nanopolymers. Nanoscale 13:16465

36. Tran VV, Tran NHT, Hwang HS, Chang M (2021) Development strategies of conducting polymer-based electrochemical biosensors for virus biomarkers: potential for rapid COVID-19 detection. Biosens Bioelectron 182:113192

37. Avelino KYPS, dos Santos GS, Frías IAM, Silva-Junior AG, Pereira MC, Pitta MGR, de Araújo BC, Errachid A, Oliveira MDL, Andrade CAS (2021) Nanostructured sensor platform based on organic polymer conjugated to metallic nanoparticle for the impedimetric detection of SARSCoV-2 at various stages of viral infection. J Pharm Biomed 206:114392

38. Raziq A, Kidakova A, Boroznjak R, Reut J, Opik A, Syritski V (2021) Development of a portable MIP-based electrochemical sensor for detection of SARS-CoV-2 antigen. Biosens Bioelectron 178:113029

39. Zaidi SA (2021) An overview of bio-inspired intelligent imprinted polymers for virus determination. Biosensors 11:89

40. Herrera-Chacón A, Cetó X, delValle M (2021) Molecularly imprinted polymers - towards electrochemical sensors and electronic tongues. Anal Bioanal Chem 413:6117-6140

41. Ratautaite V, Boguzaite R, Brazys E, Ramanaviciene A, Ciplys E, Juozapaitis M, Slibinskas R, Bechelany M, Ramanavicius A (2021) Molecularly imprinted polypyrrole based sensor for the detection of SARS-COV-2 spike glycoprotein. In press

42. Jindal S, Gopinath P (2020) Nanotechnology based approaches for combatting COVID-19 viral infection. Nano Express 1:022003

43. Talebian S, Conde J (2020) Why go nano on COVID-19 pandemic? Matter 3:598

44. Zhang Z, Ji D, He H, Ramakrishna S (2021) Electrospun ultrafine fibers for advanced face masks. Mater Sci Eng R Reports 143:100594

45. Tebyetekerwa M, Xu Z, Yang S, Ramakrishna S (2020) Electrospun nanofibers-based face masks. Adv Fiber Mater 2:161

46. Chowdhury MA, Shuvho MBA, Shahid MA, Haque AKMM, Kashem MA, Lam SS, Ong HC, Uddin MA, Mofijur M (2021) Prospect of biobased antiviral face mask to limit the coronavirus outbreak. Environ Res 192:110294

47. Das O, Neisiany RE, Capezza AJ, Hedenqvist MS, Försth M, Xu Q, Jiang L, Ji D, Ramakrishna S (2020) The need for fully bio-based facemasks to counter coronavirus outbreaks: a perspective. Sci Total Environ 736:139611

48. Akduman C (2019) Cellulose acetate and polyvinylidene fluoride nanofiber mats for N95 respirators. J Ind Text. https://doi.org/10.1177/1528083719858760

49. Zhong H, Zhu Z, Lin J, Cheung CF, Lu VL, Yan F, Chan CY, Li G (2020) Reusable and recyclable graphene masks with outstanding superhydrophobic and photothermal performances. ACS Nano 14:6213

50. Norrrahim F, Kasim NAM, Feizal V, Yunus WMZW (2021) Cationic nanocellulose as promising candidate for filtration material of COVID-19: a perspective. Appl Sci Eng Prog 14:1-8

51. Leung WWF, Sun Q (2020) Electrostatic charged nanofiber filter for filtering airborne novel coronavirus (COVID-19) and nano-aerosols. Sep Purif Technol 250:116886

52. Rai PK, Usmani Z, Thakur VK, Gupta VK, Mishra YK (2020) Tackling COVID-19 pandemic through nanocoatings: confront and exactitude. Curr Res Green Sustain Chem 3:100011

53. Muzata TS, Gebrekrstos A, Ray SS (2021) Recent progress in modified polymer-based PPE in fight against COVID-19 and beyond. ACS Omega 6:28463-28470

54. Hutasoit N, Kennedy B, Hamilton S, Luttick A, Rahman Rashid RA, Palanisamy S (2020) SarsCoV-2 (COVID-19) inactivation capability of copper-coated touch surface fabricated by cold-spray technology. Manuf Lett 25:93

55. He L, Zhao J, Wang L, Liu Q, Fan Y, Li B, Yu YL, Chen C, Li YF (2020) Using nano-selenium to combat Coronavirus Disease 2019 (COVID-19)? Nano Today 2019:124086

56. Mahmoud HK, Asghar BH, Harras MF, Farghaly TA (2020) Nano-sized formazan analogues: Synthesis, structure elucidation, antimicrobial activity and docking study for COVID-19. Bioorg Chem 105:104354 
57. Valizadeh H, Abdolmohammadi-vahid S, Danshina S, Ziya Gencer M, Ammari A, Sadeghi A, Roshangar L, Aslani S, Esmaeilzadeh A, Ghaebi M, Valizadeh S, Ahmadi M (2020) Nano-curcumin therapy, a promising method in modulating inflammatory cytokines in COVID-19 patients. Int Immunopharmacol 89:107088

58. Abo-zeid Y, Ismail NS, McLean GR, Hamdy NM (2020) A molecular docking study repurposes FDA approved iron oxide nanoparticles to treat and control COVID-19 infection. Eur J Pharm Sci 153:105465

59. Nandi DK, Mitra M (2020) Herbal Gold nanoparticles for attenuating pandemic infection of COVID-19 virus. J Nanomed Nanotechnol 11:9

60. Mallakpour S, Abdolmaleki A, Borandeh S (2014) Covalently functionalized graphene sheets with biocompatible natural amino acids. Appl Surf Sci 307:533

61. Srivastava AK, Dwivedi N, Dhand C, Khan R, Sathish N, Gupta MK, Kumar R, Kumar S (2020) Potential of graphene-based materials to combat COVID-19: properties, perspectives, and prospects. Mater Today Chem 18:100385

62. Kumar Raghav P, Mohanty S (2020) Are graphene and graphene-derived products capable of preventing COVID-19 infection? Med Hypotheses 144:110031

63. Ishack S, Lipner SR (2020) Applications of 3D printing technology to address COVID-19-related supply shortages. Am J Med 133:771

64. Advincula RC, Dizon JRC, Chen Q, Niu I, Chung J, Kilpatrick L, Newman R (2020) Additive manufacturing for COVID-19: devices, materials, prospects, and challenges. MRS Commun 10:413

65. Nazir A, Azhar A, Nazir U, Liu YF, Qureshi WS, Chen JE, Alanazi E (2020) The rise of 3D printing entangled with smart computer aided design during COVID-19 era. J Manuf Syst In press. https:// doi.org/10.1016/j.jmsy.2020.10.009

66. Zuniga JM, Cortes A (2020) The role of additive manufacturing and antimicrobial polymers in the COVID-19 pandemic. Expert Rev Med Devices 17:477

67. Pedraja J, Maestre JM, Rabanal JM, Morales C, Aparicio J, del Moral I (2020) Role of 3D printing in the protection of surgical and critical care professionals in the COVID-19 pandemic. Rev Española Anestesiol Reanim 67:417

68. Tarfaoui M, Nachtane M, Goda I, Qureshi Y, Benyahia H (2020) 3D printing to support the shortage in personal protective equipment caused by COVID-19 pandemic. Materials 13:3339

69. Attaran M (2020) 3D printing role in filling the critical gap in the medical supply chain during COVID-19 pandemic. Am J Ind Bus Manag 10:988

70. Ahmed MK, Afifi M, Uskokovi V (2020) Protecting healthcare workers during COVID-19 pandemic with nanotechnology: a protocol for a new device from Egypt. J Infect Public Health 13:1243

71. Goswami M, Yadav AK, Chauhan V, Singh N, Kumar S, Das A, Yadav V, Mandal A, Tiwari JK, Siddiqui H, Ashiq M, Sathish N, Kumar S, Biswas D, Srivastava AK (2021) Facile development of graphene-based air filters mounted on a 3D printed mask for COVID-19. J Sci-Adv Mater Dev 6:407-414

72. Nicholson K, Henke-Adams A, Henke DM, Kravitz AV, Gay HA (2021) Modified full-face snorkel mask as COVID-19 personal protective equipment: Quantitative results. HardwareX 9:e00185

73. Corpet DE (2021) Why does SARS-CoV-2 survive longer on plastic than on paper? Med. Hypotheses 146:110429

74. Tarfaoui M, Nachtane M, Goda I, Qureshi Y, Benyahia H (2020) 3D Printing to support the shortage in personal protective equipment caused by COVID-19 pandemic. Int J Adv Manuf Technol 110:2913

75. Aragaw TA (2020) Surgical face masks as a potential source for microplastic pollution in the COVID-19 scenario. Mar Pollut Bull 159:111517

76. Vanapalli KR, Sharma HB, Ranjan VP, Samal B, Bhattacharya J, Dubey BK, Goel S (2021) Challenges and strategies for effective plastic waste management during and post COVID-19 pandemic. Sci Total Environ 750:141514

77. Gorrasi G, Sorrentino A, Lichtfouse E (2020) Back to plastic pollution in COVID times. Environ Chem Lett 19:1-4

78. Ullah S, Ullah A, Lee J, Jeong Y, Zhu C, Il Joo K, Cha HJ, Kim I (2020) Reusability comparison of melt-blown vs. nanofiber face mask filters for use in the coronavirus pandemic. ACS Appl Nano Mater 3:7231

79. Wang D, Sun BC, Wang JX, Zhou YY, Chen ZW, Fang Y, Yue WH, Liu SM, Liu KY, Zeng XF, Chu GW, Chen JF (2020) Can masks be reused after hot water decontamination during the COVID19 pandemic? Engineering 6:1115-1121 
80. Mallakpour S, Behranvand V (2017) Hybrid polymer composite materials: applications. Thakur VK, Thakur MK, A. Pappu A (Eds) Elsevier, Amsterdam, Netherlands 2017, Ch. 7

81. Chakraborty I, Maity P (2020) COVID-19 outbreak: migration, effects on society, global environment and prevention. Sci Total Environ 728:138882

82. Anjankar Ashish P, Anjankar Vaibhav P, Anjankar Anil J, Lata K (2020) Positive aspects of COVID 19 pandemic: a blessing in disguise. Int J Res Pharm Sci 11:187

83. Patrício Silva AL, Prata JC, Walker TR, Duarte AC, Ouyang W, Barcelò D, Rocha-Santos T (2021) Increased plastic pollution due to COVID-19 pandemic: Challenges and recommendations. Chem Eng J 405:126683

Publisher's Note Springer Nature remains neutral with regard to jurisdictional claims in published maps and institutional affiliations. 